\title{
Monitoring reinforcement corrosion of concretes designed for nuclear facilities
}

\author{
${ }^{1}$ Comisión Nacional de Energía Atómica - Gerencia de Materiales-Departamento de Corrosión: Av. Gral. Paz 1499- \\ San Martín (1650), San Martín, Buenos Aires, Argentina. \\ e-mail: dvazquez@cnea.gov.ar; duffo@cnea.gov.ar \\ ${ }^{2}$ Universidad Nacional de San Martín, Instituto Sabato, Av. Gral. Paz 1499- San Martín (1650), San Martín, Buenos \\ Aires, Argentina. \\ ${ }^{3}$ Consejo Nacional de Investigaciones Científicas y Técnicas: Av. Gral. Paz 1499- San Martín (1650), San Martín, Bue- \\ nos Aires, Argentina.
}

\begin{abstract}
The facilities designed for the peaceful activities of nuclear energy are made with different materials, among them, reinforced concrete. This material, in addition to being structural, is a barrier for isolation and confinement from the environment of the radioactive materials. One of its degradation mechanisms is the corrosion of the reinforcement, a frequent cause of premature failure in service. Consequently, it is essential to study this degradation mechanism in formulations developed for this purpose, as well as the development and implementation of monitoring techniques.

The objective of this work is to compare, from the corrosion of reinforcement point of view, two concrete formulations, one made with ordinary portland cement and the other with pozzolanic portland cement. Both formulations are candidate for some nuclear applications, such as the Low Radioactive Waste disposal facilities, whose durability requirement is higher than 300 years. The results of approximately four years of monitoring are presented. The parameters followed are: corrosion potential and corrosion rate of the reinforcements, electrical resistivity, oxygen flow, internal temperature and carbonation rate of concrete. These parameters were measured and monitored in reinforced concrete specimens by embedded sensors previously developed in our laboratory. Also, unreinforced specimens were prepared to measure the carbonation rate. The presence of reinforcements provides the possibility of monitoring directly on them the corrosion potential, the corrosion rate and electrical resistivity of concrete, using on-surface electrodes provided by a commercial instrument. This allows the comparison of the parameters monitored by embedded sensors and the on-surface electrodes.
\end{abstract}

Keywords: Reinforced concrete corrosion; durability of reinforced concrete; nuclear materials.

\section{INTRODUCTION}

In the Argentine Republic are carried out many activities related with the use peaceful nuclear energy. These activities include, among others, the research and development of basic and nuclear technology areas, the operation of important facilities in charge of the production of radioisotopes for medical and industrial applications, projects in connection with the nuclear fuel cycle, mining and uranium processing activities, manufacturing of fuel elements, and the operation of three nuclear power plants. As a result of such activities performed in the nuclear field by private and public entities, various types of radioactive waste are being produced; among them, low radioactive waste (LRW) and high radioactive spent fuel from nuclear reactors. The National Atomic Energy Commission (CNEA) in the implement authority to perform all activities related to the radioactive waste management, taking part of the Radioactive Waste Management National Program (PNGRR) (1).

The LRW must be confined and isolated from the environment for a period of three hundred years (2), so it is mandatory a durability higher than this period. The reinforced concrete is the main material of a LRW disposal facilities, thus it is important the study of its degradation mechanisms and also monitoring techniques to control the integrity of the structures in service to ensure the mentioned durability. The deterioration of reinforced concrete can be caused by different degradation mechanisms, being the rebar 
corrosion, one of the most frequent cause of damage.

A characteristic of the reinforced concrete is that during the curing, a highly alkaline pore solution is produced ( $\mathrm{pH}$ between 13.0 and 13.8), promoting the formation of a thermodynamically stable passive layer in the interface between steel and concrete (3). According to the model of Tuutti (4), the service life of a structure can be divided in two stages: initiation and propagation. In the initiation period, aggressive species, such as carbon dioxide and/or chloride, penetrate by diffusion mechanisms because of the concrete porosity. As a consequence, the amount of aggressive species in the concrete increases and the rebar remains passive while the concentration around it is lower than a threshold value. When the concentration of aggressive species exceeds this threshold, the passive layer is destroyed and the propagation stage starts, which leads to active corrosion if water and oxygen are present on the rebar surface. During this last stage, rust spots and cracks appear on the surface of the structure, due to the expansion of the corrosion products, whose volume are between 2 and 3 times greater than the steel they are derived from (5). Due to the mentioned durability requirement for a LRW disposal facility, it is required a first stage length of, at least, three hundred years.

The analysis of the behaviour of the rebar in a structure, from the corrosion point of view, can be carried out by monitoring different parameters, among them: corrosion rate, corrosion potential, concrete resistivity, oxygen availability, temperature and carbonation rate (carbon dioxide penetration) in the concrete. With the exception to carbonation rate, all parameters are usually monitored by non-destructive techniques with sensors embedded in the concrete, and some designs were reported by Duffó et al. (6) and Martinez et al. (7). In addition, there are commercial portable instruments that implement different non-destructive techniques to measure electrical resistivity of the concrete, corrosion potential and corrosion rate of the reinforcement. Those instruments implement on-surface counter electrode (CE) and reference electrode (RE) electrode, in addition to a guard electrode which allows measurements on localized zones of a structure (7).

The ranges of the parameters monitored to be considered favourable or not for a required application are studied and established in the literature only for corrosion potential and corrosion rate. The ASTM 876 standard (8) ranges the corrosion potential that predicts low, intermediate or high corrosion risk. Also, different ranges of corrosion rate to be considered as negligible, low, moderate, intermediate and high were established by Andrade et al. (9). In the case of electric resistivity of concrete there is not agreement in the literature to obtain conclusions like as the two parameters previously mentioned.

As regards to carbonation rate, its limit value is determined by the service life of the structure (the initiation stage in the Tuutti's service life model) and the concrete cover. It means that the depth of carbonation during the service life must be lower than the concrete cover to guarantee passivity.

In the present work, a monitoring of the mentioned parameters was performed during approximately 1600 days in reinforced concrete specimens, using corrosion embedded sensors and measuring on the rebar with auxiliary on-surface electrodes. The measurements on the rebar were performed using a commercial instrument (GECOR 6), which uses an array of on-surface guard, CE and RE electrodes. Also, the carbonation rate was tested on concrete specimens of the same batch that the reinforced concrete specimens. The results obtained, allows us to make a comparison between the two types of concrete, one with ordinary portland cement and the other with pozzolanic portland cement, from the rebar corrosion point of view. The analysis is also focused in the feasibility of two types of concrete to be employed in the construction of an LRW repository.

\section{MATERIALS AND METHODS}

The work was performed on specimens made with ordinary portland cement (CPN) and pozzolanic portland cement (CPP). Both types of cements comply with the requirements of the Argentinean standard IRAM 50000 (10). The coarse aggregate used was granitic crushed stone of nominal maximum size of $0.0019 \mathrm{~m}$ and the fine aggregate was river siliceous sand. The dosages of the admixtures were defined to ensure low water content compatible with the required consistency. This possibility was given by the use of high and intermediate-range water reducer. Table 1 shows the composition of the admixtures for two types of concretes and, in table 2, the properties of the intermediate-range water reducer is included. The casting was made in layers of $25 \mathrm{~cm}$ high and each of them was compacted by a vibrator (the first layer was vibrated before the casting of the second layer). The monitoring of corrosion potential, corrosion rate of the rebar, electrical resistivity, oxygen availability and temperature of concrete were performed on four prototypes of reinforced concrete, two of them made with CPN and the others with CPP, whose dimensions are $0.5 \times 0.60 \times 0.15 \mathrm{~m}^{3}$. The prototypes were exposed to the external environment on a building roof placed in Constituyentes Atomic Center (coordinates: -34.57,-58.51), which is a research center in Buenos Aires city aimed to support the nuclear energy applications in Argentina. The CPN prototypes, as well as the CPP ones, 
were in perpendicular positions one to each other, simulating a corner between two walls of a radioactive waste container (Figure 1 (a)).

Table 1: Proportions of constituents in concretes.

\begin{tabular}{|l|l|l|}
\hline \multirow{2}{*}{ Materials } & \multicolumn{2}{|c|}{ Concretes } \\
\cline { 2 - 3 } & CPN & CPP \\
\hline Water & 140 & 140 \\
\hline Cement & 400 & - \\
\hline Fine Aggregate & 920 & 895 \\
\hline Coarse Aggregate & 980 & 980 \\
\hline Additive M & 3.2 & 4.0 \\
\hline Additive D & 6.0 & 8.0 \\
\hline Fresh State & CPN & CPP \\
\hline Slump (mm) & 185 & 200 \\
\hline Unitary weight $\left(\mathrm{kg} / \mathrm{m}^{3}\right)$ & 2442 & 2414 \\
\hline Entrained air $(\%)$ & 3.5 & 4.3 \\
\hline
\end{tabular}

Table 2: Characteristic of the dosages.

\begin{tabular}{|l|l|l|c|}
\hline Type & Density & Composition & Solid Content (\%) \\
\hline M & 1.142 & Modified Lignosulfonate & 52.7 \\
\hline D & 1.158 & Naphtalene Sulfonate & 49.3 \\
\hline
\end{tabular}

At the same time, prismatic specimens for measuring carbonation rate were made with the same batch that the prototypes. The number of specimens of every concrete were three and the dimensions $0.07 \times 0.07 \times 0.30 \mathrm{~m}^{3}$. These specimens were exposed to the external environment together with the prototypes (Figure $1(\mathrm{~b})$ ).

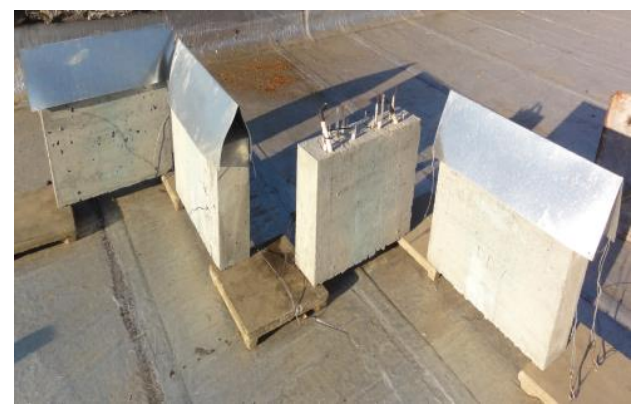

(a)

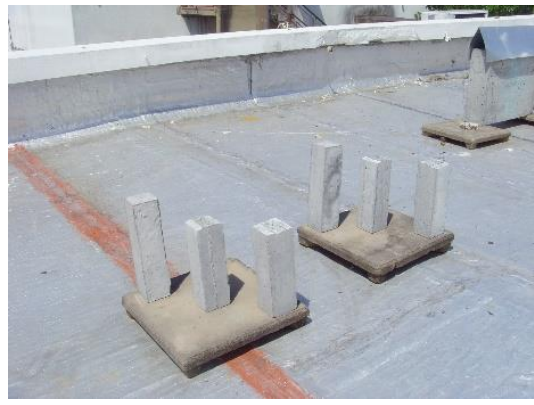

(b)

Figure 1: (a) Prototypes exposed to the external environment. (b) Specimens for carbonation tests exposed together with the prototypes showed in (a).

Each prototype was reinforced with four bars and an electro-welded mesh Sima ${ }^{\circledR}$ with $0.15 \mathrm{~m}$ grid. In both cases, the diameter of these frames is $0.01 \mathrm{~m}$ and were manufactured by Acindar Company. The chemical composition of the steel rebar is the following: $\mathrm{C}, 0.41 \% ; \mathrm{Mn}, 0.73 \% ; \mathrm{Cu}, 0.27 \% ; \mathrm{Ni}, 0.13 \% ; \mathrm{Si}$, $0.28 \% ; \mathrm{P},<0.01 \% ; \mathrm{S}, 0.02 \% ; \mathrm{N}, 0.008 \%$; Fe, balance. The concrete cover depth was of $0.05 \mathrm{~m}$ with respect to one of the faces of $0.50 \times 0.60 \mathrm{~m}^{2}$ and each bar was placed in the same concrete cover depth of the mesh but with respect to the analogue opposite face. The Figures 2 (a) and (b) show a cross sectional view of the prototypes and in these figures the position of the bars and the mesh can be observed. The exposed length of the bars is of $0.20 \mathrm{~m}$, which was demarcated with epoxy paint. The bars, as well as the meshes have welded copper contacts, extending toward the outside of the prototypes to allow connections for the electrochemical measurements. Every welding contact was sealed with epoxy resin to avoid its deterioration. 


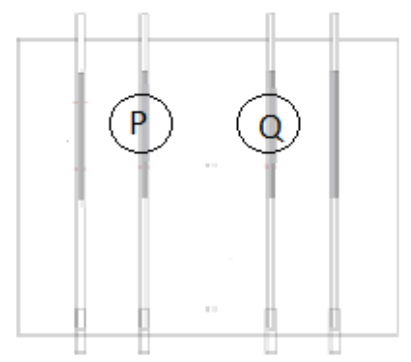

(a)

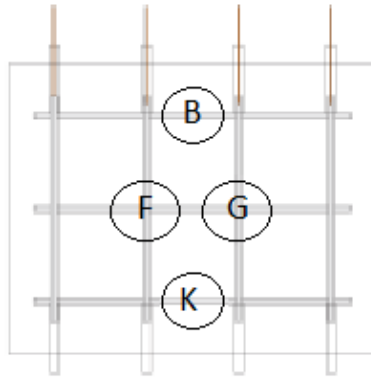

(b)

Figure 2: View of the electrodes and rebar position. (a) Bars. (b) Electro-welded mesh.

The prototypes were instrumented by two embedded corrosion sensors, which allow the simultaneous monitoring of the mentioned parameters (7). In each prototype one sensor was attached to a bar, and the other to the mesh, named as S1 and S2 for CPN prototype and S3 and S4 for CPP prototype. Every sensor consist of an embedded electrodes system that allows the implementation of electrochemical techniques. A steel bar, with the same characteristics of a steel rebar for concrete, is used as embedded WE in the sensor, and two stainless steel bars, to ensure enough area for the electrochemical reactions, are used as CE. The RE is a wire of titanium coated with titanium oxide doped with iridium and tantalum, characterized as RE by Duffó et al. (11). The galvanostatic pulse technique is used for measuring the corrosion rate. This technique is based on the application of an input current pulse between a working electrode (WE), and a CE. During the galvanostatic condition there is an output potential evolution with respect to the RE, which is analysed to calculate the polarization resistance ( $\mathrm{Rp}$ ), according to Andrade et al. (12). The Rp is required to calculate the corrosion rate by the Stern and Geary equation (13). At the same time, the two stainless steel bars and the RE mentioned above are used to measure oxygen availability and electrical resistivity of the concrete (7). The instrument used to perform these measurements is a potentiostat/galvanostat, Gamry model Reference 600.

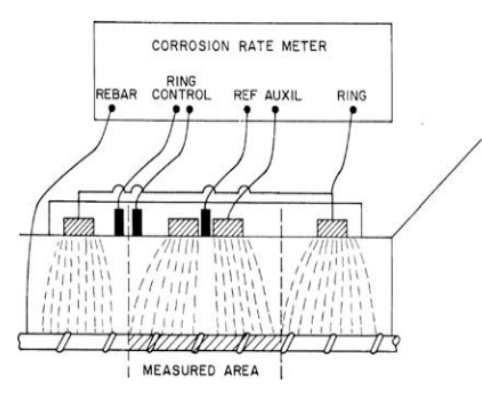

(a)

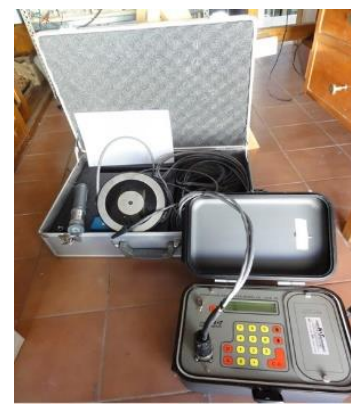

(b)

Figure 3: (a) Description scheme of the measurements, implementing superficial RE, CE and guard electrode. (b) Commercial potentiostat GECOR6.

Besides, measurements were carried out to monitor the corrosion rate and the corrosion potential on the rebar. The locations monitored on the bars were P and Q, while on the electro-welded mesh were $\mathrm{F}$ and $\mathrm{G}$ with welding, and B and K smooth, as showed in Figure 2 (b) and (c). Again, the measurements of the corrosion rate were made using the galvanostatic pulse technique, but in a different way that in the sensors. In this case, an on-surface guard electrode is implemented, which is able to confine the current flow, between the WE (bar) and the on-surface CE (stainless steel), in a defined exposed length approximately of $10 \mathrm{~cm}$, as showed in Figure 3 (a) (5). The instrument used was the commercial GECOR 6 (James Instruments), showed in Figure 3 (b), which applies a galvanostatic pulse for a period of 60 seconds.

\section{RESULTS AND DISCUSSION}

Figures 4 through 8 present the results of the monitoring by the sensors. Figure 4 (a) and (b) show the temperature registered for the prototypes of CPN and CPP, respectively. The internal temperatures are presented together with the environment temperature. The measurements showed that, in general, the temperature inside the material is greater than the environment, with a largest recorded difference of about 
$15{ }^{\circ} \mathrm{C}$. The highest temperature differences are founded in sunny days due to the material exposed to solar radiation storage thermal energy, raising its temperature respect to air temperature, unlike in the cloudy days when the temperatures of the material and environment are similar.

In Figure 5 (a) and (b) the evolution of the corrosion potential for CPN and CPP prototypes is presented, respectively, and its units are expressed in volts against the copper-saturated copper sulphate electrode (Vcse). At the beginning, it is distinguished that in both cases the values belong to intermediate corrosion risk according to ASTM 876 (8). However, the evolution was favourable, since in both concretes the values in the first 600 days rise to the limit between intermediate risk and low corrosion risk. At the same time, the values of CPP prototypes are more frequently in low corrosion risk range than the values of CPN prototypes.

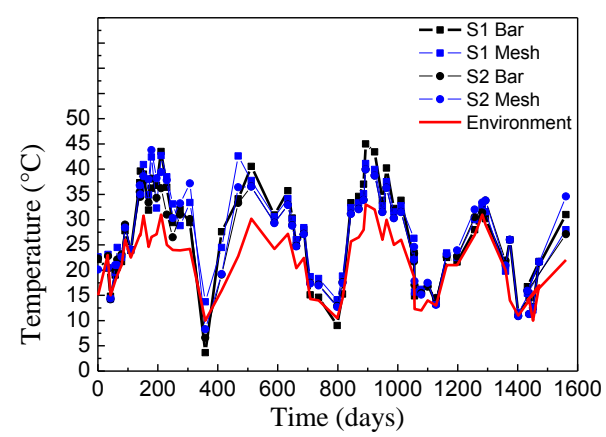

(a)

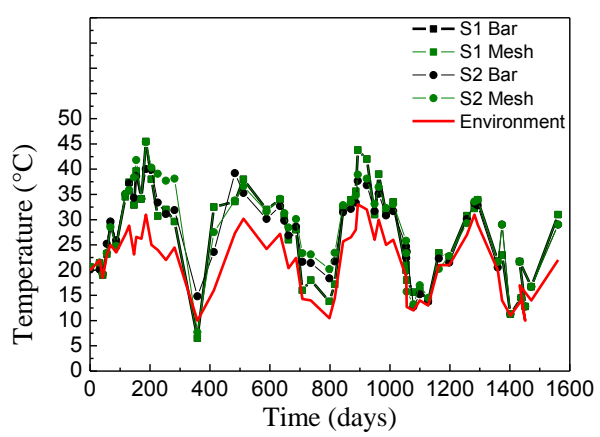

(b)

Figure 4: Internal temperature monitored by the sensors and ambient temperature. (a) CPN. (b) CPP.

The Figures 6 (a) and (b) shows the corrosion rate and its comparison with the temperature inside the CPN and CPP prototypes, respectively, and the dotted line is the limit value $(0.1 \mu \mathrm{m} /$ year $)$ for LRW repositories (2). It can be seen the influence of the temperature in the corrosion rate, so that the higher the temperature, the higher corrosion rate. In both type of concrete, the values started one order of magnitude higher than the limit and decreased to be currently around twice the limit value.

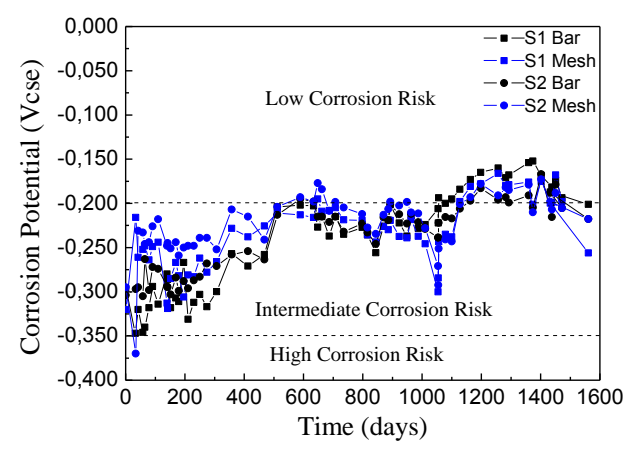

(a)

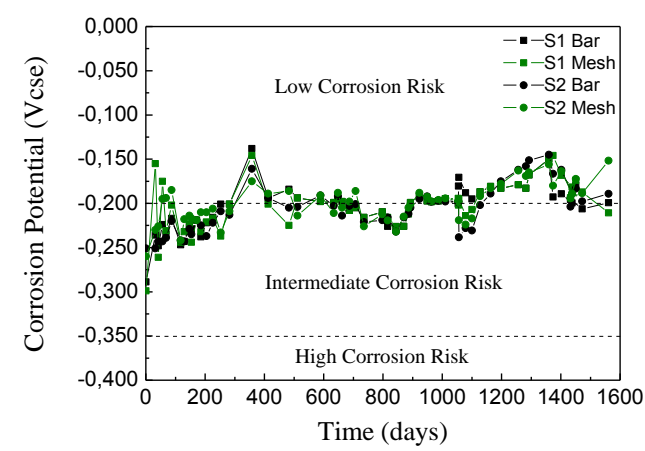

(b)

Figure 5: Evolution of the corrosion potential monitored by the sensors. (a) CPN. (b) CPP.

In Figure 7 it is plotted the temporal evolution of the availability of oxygen expressed in $\mu \mathrm{A} / \mathrm{cm}^{2}$, together with the internal temperature. It can be seen that the oxygen flow has a similar behaviour as the corrosion rate, being higher the higher the temperature, reaching a maximum value of $100 \mu \mathrm{A} / \mathrm{cm}^{2}$ for both types of concrete. It is worth to mention that oxygen is the main oxidizing agent for the rebar in contact with the alkaline pore solution of the concrete; therefore the fact that the temperature increases the oxygen flow could also be related to the increase in the corrosion rate. The results showed a decreasing tendency of this parameter in both types of concrete and it is considered a positive result. In this context is expected lower values of corrosion rate due to the decreasing behaviour of the main oxidizing specie. 
Figure 8 (a) and (b) corresponds to measurements of the electrical resistivity for both concretes plotted together with the prototypes temperature values. In both concretes the parameter increases with time, being this associated to the hydration processes of the material, which reduces the water content of pores. Also, it can be appreciated that the influence of the temperature is inverse to the behaviour observed in the corrosion rate and oxygen flow.

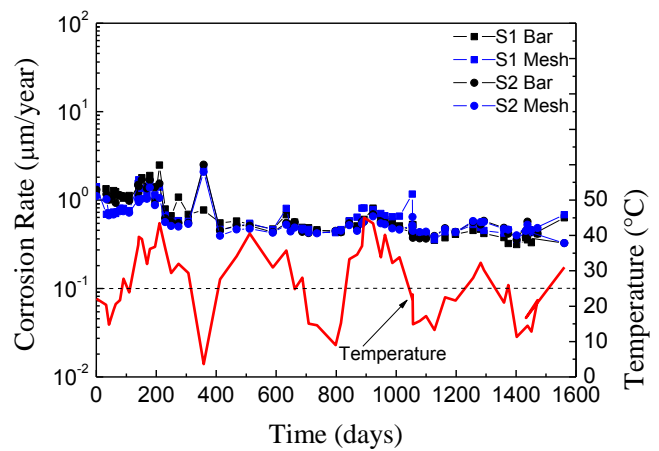

(a)

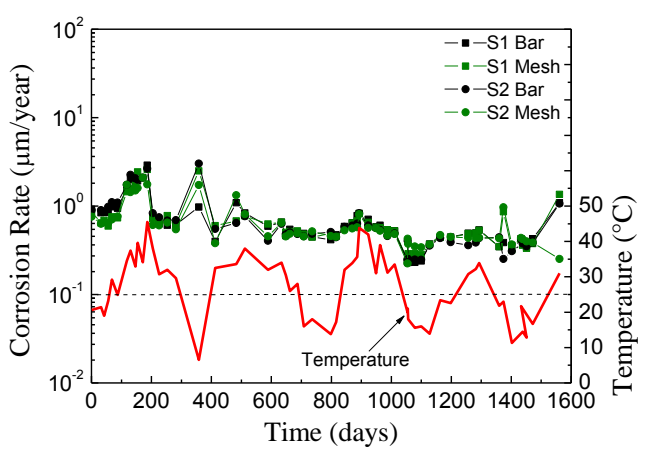

(b)

Figure 6: Evolution of the corrosion rate monitored by the sensors. (a) CPN. (b) CPP.

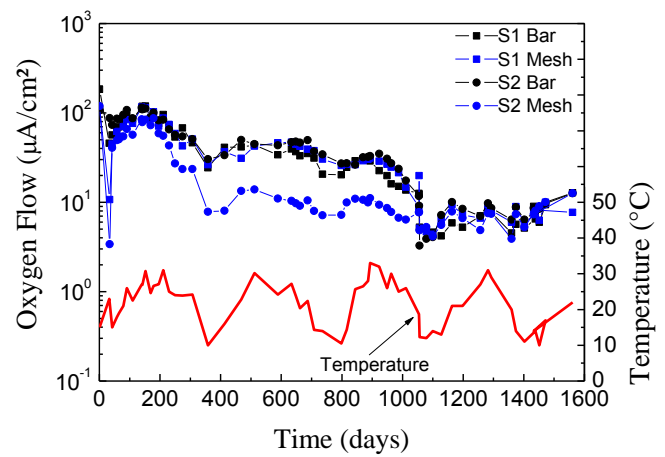

(a)

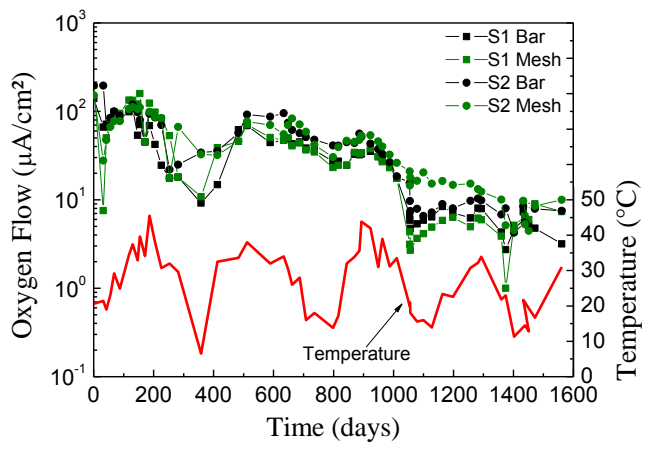

(b)

Figure 7: Evolution of the oxygen availability monitored by the sensors. (a) CPN and (b) CPP.

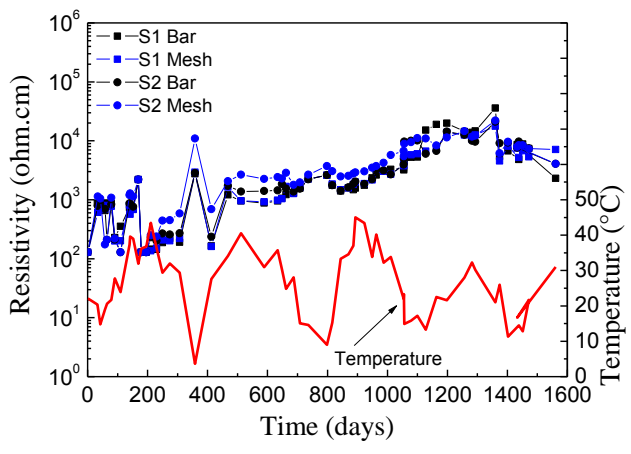

(a)

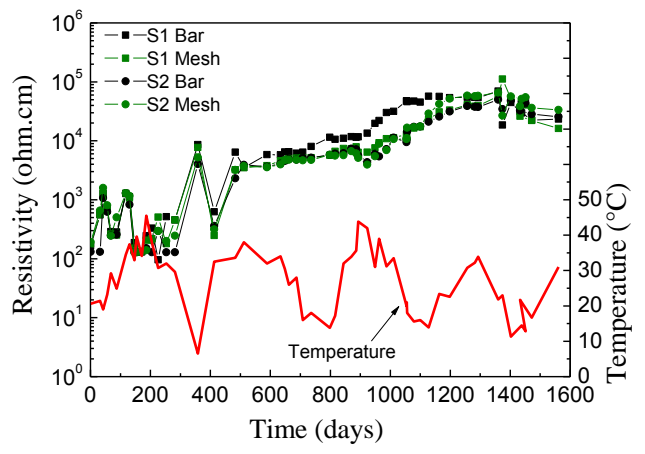

(b)

Figure 8: Evolution of the electric resistivity monitored by the sensors. (a) CPN. (b) CPP.

The Figure 9 and 10 show the results of the corrosion potential and the corrosion rate respectively, monitored by the commercial instrument on the bars, in locations $\mathrm{P}$ and $\mathrm{Q}$, and on the mesh in locations $\mathrm{F}$ and $\mathrm{G}$ (with welding) and B and $\mathrm{K}$ (smooth). For the sake of simplicity, only the values of the CPN1 and CPP1 prototypes are presented, because the values of CPN2 and CPP2 are similar to CPN1 and CPP1 
respectively.

The evolution of the corrosion potential showed low corrosion risk in the whole time of monitoring in both type of concrete (Figure 9).

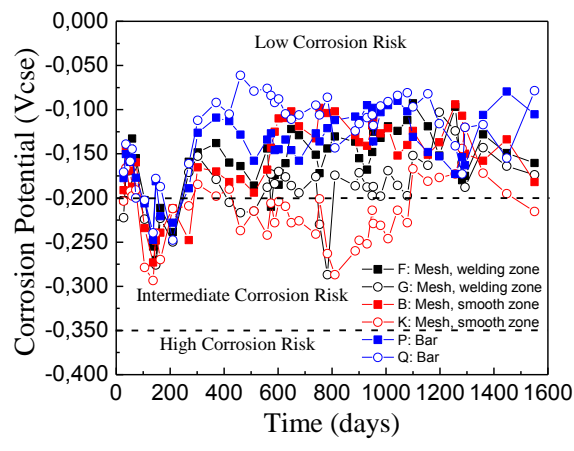

(a)

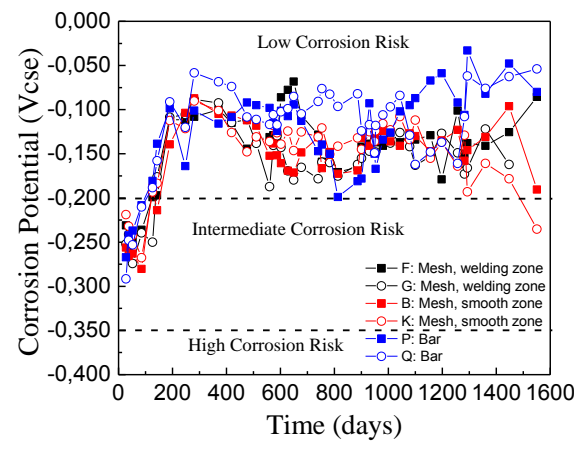

(b)

Figure 9: Temporal evolution of the corrosion potential measured with superficial RE by the commercial instrument. (a) $\mathrm{CPN}$ and (b) CPP.

Similarly to the values obtained by the sensors, the corrosion rate revealed values higher than the mentioned threshold value and the general tendency is decreasing. The values of the bars, locations $\mathrm{P}$ and $\mathrm{Q}$, were similar that those of the sensors while the values of the meshes, the locations F and G (with welding), B and $\mathrm{K}$ (smooth), were generally one order of magnitude higher than those of the bars.

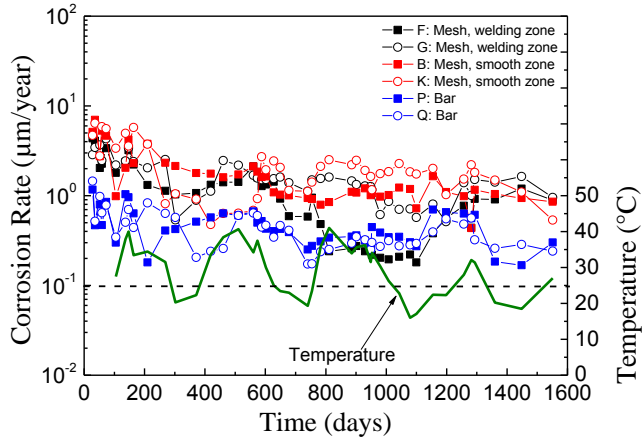

(a)

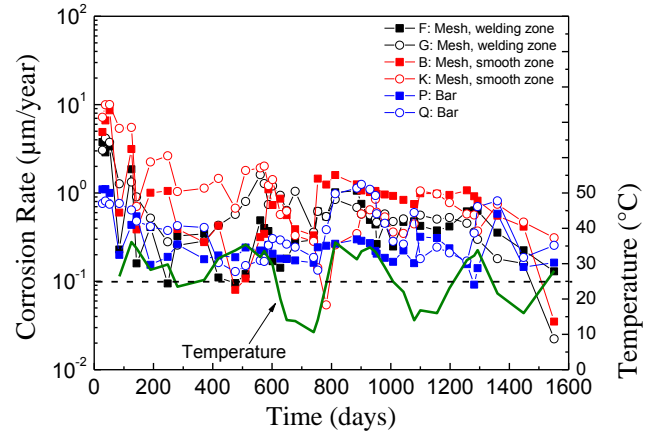

(b)

Figure 10: Monitoring of corrosion rate measured with superficial RE, CE and guard electrode by the commercial instrument. (a) CPN and (b) CPP.

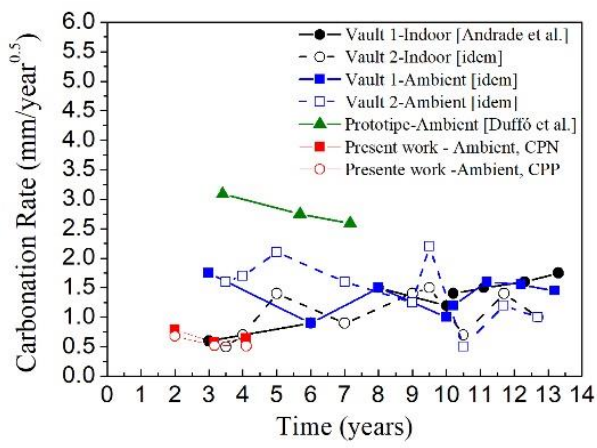

Figure 11: Comparisons of the carbonation rate in the present work with the values reported in the literature. 
In Figure 11 the values of the carbonation rate in the present work compared with those obtained by Andrade et al. (10) are presented. The mean value of the carbonation depth after approximately 4 years exposure time was $1.3 \mathrm{~mm}$ for the CPN and $1 \mathrm{~mm}$ for CPP specimens. These values give a carbonation rate ( $\mathrm{k}$ in the equation $\mathrm{x}=\mathrm{k} \cdot \mathrm{t}^{0.5}$, $\mathrm{x}$ being the carbonation depth and the exposure time), of 0.64 and 0.52 $\mathrm{mm} /$ year $^{0.5}$ for CPN and CPP concretes respectively. The penetration depth for 300 years calculated using these values of carbonation rate is lower than $15 \mathrm{~mm}$ for both types of concrete. Also, the carbonation rate obtained are similar to the smallest value reported in the literature.

\section{CONCLUSIONS}

The corrosion potential monitored by the sensors on both types of concrete prototypes showed a favourable evolution. At the beginning, they belong to the intermediate corrosion risk zone, and currently are around the limit between low and intermediate corrosion risk zone.

The corrosion potential monitored by the on-surface electrodes on the rebar of both types of concrete was in the low corrosion risk zone the whole period of monitoring.

The values of the corrosion rate monitored by the sensors in both types of concrete were decreasing, but are currently slightly higher than the threshold value established in the literature for LRW disposal facilities.

The corrosion rate monitored by the on-surface electrodes in both types of concrete presented similar tendency as those observed by the sensors. On the electro-welded mesh this parameter showed values one order of magnitude for de CPN slightly higher for the CPP concrete respectively, than those of the bars whose values are similar to the sensors.

The temperature has a direct influence on the corrosion rate and the oxygen flow and inverse on the resistivity. This effect should be carefully taken into account when applying durability models. At the same time the decreasing tendency of the corrosion rate could be related with the same behaviour showed by oxygen, which is the main oxidizing agent.

The carbonation rate values are low enough to accomplish with the service life requirement for LRW disposal facilities. It means that for the values measured, the calculated penetration along three hundred years is lower than the proposed concrete cover depth.

It is important to remark that a longer monitoring must be carried out to obtain conclusions about the feasibility of two types of concrete to be used for the construction of an LRW disposal facility. Mainly, to assure the corrosion rate were lower than the threshold value for this application, as the evolution showed to be favourable. The conclusions should be concise and represent the most important aspects found during the reported development work. They should seek to point out the scientific and/or technological and/or theoretical progress effectively achieved.

\section{BIBLIOGRAPHY}

[1] JOINT convention on the safety of spent fuel management and on the safety of radioactive waste management. http://www.cab.cnea.gov.ar/residuos/CC2003/0002-SecA.pdf (march/25/2011).

[2] SCHULTZ, F.M., ARVA, E.A. DUFFO, G.S. "Studies concerning the reinforcement corrosion of concrete vaults for intermediate-level radioactive waste disposal", in: Long Term Performance of Cementitious Barriers and Reinforced Concrete in Nuclear Power Plants and Waste Management (RILEM Publications Paris: SARL, V. L'Hostis, R. Gens, C. Gallé, 2009).

[3] CARÉ, S., BERTHAUD,Y., RAGUENEAU, F., et al., "Investigations Into the Development of Corrosion Induced Cracks in Mortar", Proceedings of the RILEM Workshop on Long Performance of Cementitious Barriers and Reinforced Concrete in Nuclear Power Plants-NUCPERF 2009, PRO 64, pp 61-69, March2009. [4] TUUTTI, K. “Corrosion of steel in concrete”, Swedish Cement and Concrete Institute, Stockholm, 1982. [5] BERTOLINI, L., ELSENER, B., PEDEFERRI, P., et al., "Corrosion of Steel in Concrete”, in: WileyVCH, Mechanisms of Corrosion, chapter 4, Germany, 2003.

[6] DUFFÓ, G., FARINA, S. "Development of an embeddable sensor to monitor the corrosion process of new and existing reinforced concrete structures". Construction and Building Materials, Vol. 23: p. 274-275, 2003

[7] MARTINEZ, I., ANDRADE, C. "Examples of reinforcement corrosion monitoring by embedded sensors in concrete structures”. Cement \& Concrete Composites, Vol. 32: p. 545-554, 2009.

[8] ASTM C 876, "Standard test method for half-cell potential for uncoated reinforcing steel in concrete". 
(1991), Philadelphia.

[9] ANDRADE, C., ALONSO, C. "Corrosion rate monitoring in the laboratory and on-site". Construction and Building Materials, v. 10: p. 315-328, 1996.

[10] ANDRADE, C., MARTÍNEZ, I., CASTELlOTE M., et al,, J. Nucl. Mater., n.358, v.82, 2006.

[11] IRAM 50000, “Cemento. Cemento para uso general. Composición, características, evaluación de la conformidad y condiciones de recepción”, Buenos Aires, 31, p. 5, 2000.

[12] GONZALEZ, J., COBO, A., GONZALEZ, M., et al., "On-site determination of corrosion rate in reinforced concrete structures by use of galvanostatic pulses”. Corrosion Science, Vol. 43, p. 611-625, 2001.

[13] STERN, M., GEARY, A. "Electrochemical Polarization”, I. J. Electrochem. Soc., Vol. 104, p. 56-63, 1957. 